\title{
Role of new anticoagulants for the prevention of venous thromboembolism after major orthopaedic surgery and in hospitalised acutely ill medical patients
}

\author{
Walter Ageno'; Alex C. Spyropoulos ${ }^{2}$; Alexander G.G. Turpie ${ }^{3}$ \\ ${ }^{1}$ University of Insubria-Ospedale di Circolo, Varese, Italy; ${ }^{2}$ University of Rochester Medical Center, Rochester, New York, USA; ${ }^{3}$ McMaster University, Hamilton, Ontario, Canada
}

\begin{abstract}
Summary
Anticoagulation therapy for the prevention of venous thromboembolic events (VTE) is indicated in patients after major orthopaedic surgery and in hospitalised acutely ill medical patients who have a high or moderate risk of VTE, respectively. Clinical trials have clearly demonstrated that short-term anticoagulation reduces the risk of VTE in these patient groups and that longer-term anticoagulation is beneficial for some indications. Evidence-based guidelines for thromboprophylaxis have been developed based on these studies. However, despite these guidelines, thromboprophylaxis is still underused, or used suboptimally, in many patients. This is, in part, because of the limitations of traditional anticoagulants such as unfractionated heparin, low-molecular-weight heparin, synthetic pentasaccharides, and vitamin $\mathrm{K}$ antagonists. Newer oral anticoagulants, such as rivaroxaban, apixaban, and dabigatran etexilate, have certain advantages over traditional agents. They can be
\end{abstract}

Correspondence to:

Alexander G. G. Turpie, MD, FRCP, FACP, FACC, FRCPC

Department of Medicine, McMaster University

Hamilton Health Sciences-General Hospital

237 Barton Street East, Hamilton, Ontario L8L 2X2, Canada

Tel.: +1 416363 6726, Fax: +1 9056289505

E-mail: turpiea@mcmaster.ca administered orally at a fixed dose without routine coagulation monitoring and have minimal food and drug interactions. These characteristics may result in better adherence to guidelines and improved patient outcomes. This review provides an overview of phase III clinical trial data for these newer anticoagulants in major orthopaedic surgery and in hospitalised acutely ill medical patients, and discusses their potential for extended use in the post-hospital discharge setting. All three newer oral anticoagulants are approved in many countries for the prevention of VTE after hip replacement or knee replacement surgery in adult patients, and it is likely that these drugs will contribute considerably towards reducing the substantial healthcare burden associated with VTE.

\section{Keywords}

Apixaban, dabigatran etexilate, medically ill, orthopaedics, rivaroxaban

Financial support:

The authors would like to acknowledge Claudia Wiedemann, who provided editorial support with funding from Bayer HealthCare Pharmaceuticals and Janssen Research \& Development, L.L.C (formerly Johnson \& Johnson Pharmaceutical Research \& Development, L.L.C.).

Received: November 11, 2011

Accepted after major revision: January 27, 2012

Prepublished online: ((Not until forms received))

doi:10.1160/TH11-11-0787

Thromb Haemost 2012; 107:

\section{Introduction}

Venous thromboembolism (VTE), which comprises deep-vein thrombosis (DVT) and pulmonary embolism (PE), causes considerable morbidity and mortality and places a substantial burden on healthcare resources $(1,2)$. Patients who undergo major orthopaedic surgery, which includes total knee replacement (TKR), total hip replacement (THR), and hip fracture surgery (HFS), are at a high risk of VTE. In this patient group, the rate of asymptomatic, objectively confirmed DVT is $40-60 \%$ without thromboprophylaxis. In comparison, patients admitted for an acute medical illness (such as infection, respiratory failure, cardiovascular disease, or neurological disease) are at a moderate risk of VTE; the rate of DVT is $10-20 \%$ (3). Oncology patients have an increased risk of new or recurrent VTE when compared with patients who do not have cancer. The risk of VTE in patients with cancer is increased by three- to five-fold for those who undergo surgery and by 6.5 -fold

for those receiving chemotherapy $(4,5)$.

The benefits of thromboprophylaxis after major orthopaedic surgery are well established (3), and clinical trials have shown that the use of anticoagulants reduces the risk of VTE in hospitalised acutely ill medical patients (6-10). Identification of patients at risk of VTE will facilitate the administration of appropriate thromboprophylaxis and reduce the incidence of VTE and its complications. VTE risk factors can be patient related (e.g. age, obesity, hormonal therapy, cancer, previous VTE, molecular thrombophilia, chronic venous insufficiency, and prolonged immobility or bed rest $>3$ days) or treatment related (e.g. type and length of surgery, and type of anaesthesia) (11-13). VTE risk factors are generally cumulative (14), and as many as $80 \%$ of patients hospitalised for DVT have three or more predisposing factors (15). Risk assessment models have been recently validated in clinical trials to predict the risk of VTE for hospitalised acutely ill medical patients $(16,17)$ or cancer patients (18); however, these are not yet routinely used. 
Several evidence-based guidelines for VTE prevention exist. For patients undergoing THR, TKR, or HFS, the American College of Chest Physicians (ACCP) guidelines recommend low-molecularweight heparin (LMWH), fondaparinux, or a vitamin $\mathrm{K}$ antagonist (VKA); unfractionated heparin (UFH) is also recommended for HFS. Thromboprophylaxis is recommended for up to 35 days after THR and HFS and for at least 10 days after TKR, and there is some evidence that continuing prophylaxis for up to 35 days after TKR is beneficial (3). The current American Academy of Orthopaedic Surgeons (AAOS) guidelines differ from those of the ACCP in that they do not recognise DVT as a critical outcome (19). The AAOS guidelines do not recommend specific anticoagulants for VTE prophylaxis in patients undergoing TKR or THR; the choice of prophylaxis and duration of treatment depends on the perceived bleeding risk of each individual patient (19). For VTE prophylaxis in hospitalised acutely ill medical patients with risk factors for VTE, the ACCP guidelines recommend low-dose UFH, LMWH, or fondaparinux. However, there are no recommendations for the optimal duration of thromboprophylaxis for acutely ill medical patients (20). Mechanical methods (graduated compression stockings and intermittent pneumatic compression) are recommended primarily for surgical and non-surgical patients with contraindications to anticoagulant thromboprophylaxis (3).

In patients with cancer who are immobilised and have an acute medical illness, low-dose UFH, LMWH, or fondaparinux are recommended by several organisations, including the ACCP, International Union of Angiology, and American Society of Clinical Oncology (ASCO) $(3,21,22)$. There is little guidance on the optimal duration of thromboprophylaxis in patients with cancer, although the ASCO guidelines recommend continuing thromboprophylaxis for the duration of hospital stay or until the patient is ambulatory. Outpatient VTE prophylaxis is recommended only for patients receiving highly thrombogenic thalidomide- or lenalidomide-based combination chemotherapy regimens.

Traditional anticoagulants have limitations: UFH, LMWH, and fondaparinux are administered parenterally; VKAs require routine coagulation monitoring for prophylaxis and have numerous food and drug interactions (23). Newer oral anticoagulants, such as the direct factor Xa inhibitors rivaroxaban and apixaban, and the thrombin inhibitor dabigatran etexilate, are being developed and have the potential to address some of these limitations. This review will provide an overview of the phase III clinical trial data for these newer anticoagulants in major orthopaedic surgery and in hospitalised acutely ill medical patients, and discuss their potential for extended use in the post-hospital discharge setting. The pharmacology of these agents and VTE prevention studies in patients undergoing THR or TKR have been reviewed previously by Ufer (24).

\section{New oral anticoagulants}

The pharmacological profiles of the newer oral anticoagulants rivaroxaban, apixaban, and dabigatran etexilate are summarised in
Table 1 (25-27). These three agents have been studied in phase III trials for VTE prevention after THR and TKR surgery ( Table 2) (28-40). Rivaroxaban $10 \mathrm{mg}$ once daily (od) $(25,41)$ and dabigatran etexilate $220 \mathrm{mg}$ od $(27,41)$ are widely approved for the primary prevention of VTE in adults after elective hip or knee replacement surgery. Apixaban $2.5 \mathrm{mg}$ twice daily (bid) has been approved recently for VTE prevention in this patient group in the EU (26). For VTE prevention in acutely ill medical patients, rivaroxaban and apixaban have recently completed phase III trials $(42,43)$ There are currently no phase III trials for dabigatran etexilate in this population.

\section{VTE prevention after major orthopaedic surgery}

Anticoagulation therapy is indicated for all patients undergoing TKR or THR, with the aim to achieve an optimal balance between VTE prevention and the risk of bleeding (44). For both types of procedure, post-surgery hospital stays are typically 3-10 days (45). There is a continued risk of VTE after hospital discharge; therefore, post-discharge administration of effective, well-tolerated, and convenient anticoagulants would be beneficial for patients.

Rivaroxaban was evaluated in four phase III studies: RECORD1 and RECORD2 (THR studies), and RECORD3 and RECORD4 (TKR studies) (28-31). RECORD1 compared rivaroxaban $10 \mathrm{mg}$ od with the LMWH enoxaparin $40 \mathrm{mg}$ od for 31-39 days (28). RECORD2 compared rivaroxaban $10 \mathrm{mg}$ od for 31-39 days with enoxaparin $40 \mathrm{mg}$ od for 10-14 days followed by placebo (29). RECORD3 and RECORD4 compared rivaroxaban $10 \mathrm{mg}$ od with enoxaparin $40 \mathrm{mg}$ od or $30 \mathrm{mg}$ bid, respectively, for 10-14 days (30, 31). In all four trials rivaroxaban was superior to the enoxaparin regimens in terms of the primary efficacy outcome (composite of any DVT, non-fatal PE, and all-cause mortality), without significant differences in the rates of major bleeding (28-31). A pooled analysis of the four RECORD studies indicated that rivaroxaban regimens reduced symptomatic VTE plus all-cause mortality compared with enoxaparin regimens; this finding was consistent across patient subgroups, irrespective of age, gender, body mass index, and renal function (32).

Apixaban was evaluated in three phase III clinical trials. In the ADVANCE-1 study in TKR, apixaban (2.5 mg bid) for 10-14 days did not meet the prespecified statistical criteria for non-inferiority versus enoxaparin (30 mg bid) in terms of efficacy (composite of any DVT, non-fatal PE, and all-cause mortality) (33). However, in both ADVANCE-2 (TKR; 10-14 days) and ADVANCE-3 (THR; 35 days), apixaban $2.5 \mathrm{mg}$ bid showed superior efficacy to enoxaparin $40 \mathrm{mg}$ od $(34,35)$. In all three studies, there were no significant differences in the rates of major bleeding between apixaban and enoxaparin (33-35). A meta-analysis of ADVANCE-1, ADVANCE-2, and a phase II study of apixaban in patients undergoing TKR surgery showed that apixaban was more effective than enoxaparin in reducing the risk of proximal DVT but no more effective in reducing the risk of PE or all-cause mortality (46). 
Table 1: Summary of pharmacological profiles of apixaban, rivaroxaban and dabigatran etexilate.

\begin{tabular}{|c|c|c|c|}
\hline & Rivaroxaban (25) & Apixaban (26) & $\begin{array}{l}\text { Dabigatran } \\
\text { etexilate (27) }\end{array}$ \\
\hline Target & Factor Xa & Factor Xa & Thrombin \\
\hline Prodrug & No & No & Yes \\
\hline Bioavailability (\%) & $\sim 80$ & $\sim 50$ & 6 \\
\hline Half-life, hours & $5-13$ & $\sim 13$ & $12-17$ \\
\hline Time to peak, $T_{\max }$, hours & 3 & $3-4$ & $0.5-2.0$ \\
\hline Renal elimination (\%) & $\begin{array}{l}33 \text { as unchanged drug; } \\
33 \text { as inactive metabolites }\end{array}$ & $\sim 27$ & $\sim 85$ \\
\hline Drug interactions* & $\begin{array}{l}\text { Potent inhibitors of both CYP3A4 and P-gp, CYP3A4 in- } \\
\text { ducers, anticoagulants, NSAIDs, platelet aggregation in- } \\
\text { hibitors }\end{array}$ & $\begin{array}{l}\text { Potent inhibitors of } \\
\text { CYP3A4 }\end{array}$ & $\begin{array}{l}\text { Potent inhibitors or inducers of P-gp, anticoagulants } \\
\text { NSAIDs, platelet aggregation inhibitors }\end{array}$ \\
\hline Antidote & None & None & None \\
\hline Coagulation monitoring & No & No & No \\
\hline Dosing & Once daily ${ }^{\dagger}$ & Twice daily ${ }^{\ddagger}$ & Once daily \\
\hline
\end{tabular}

${ }^{*}$ Clinically significant drug interactions. ${ }^{\dagger}$ Dosing approved in many countries (including the USA) for thromboprophylaxis after elective hip or knee replacement surgery, and used in a study assessing rivaroxaban for thromboprophylaxis in medically ill patients (MAGELLAN). "Dosing used in THR and TKR studies (ADVANCE-2 and ADVANCE-3) that met statistical non-inferiority criteria for apixaban versus enoxaparin, and used in a study assessing apixaban for thromboprophylaxis in medically patients (ADOPT). ${ }^{\S}$ Dosing approved in several countries (not including the USA) for thromboprophylaxis after elective hip or knee replacement surgery. CYP3A4, cytochrome P450 3A4; NSAID, non-steroidal anti-inflammatory drug; P-gp, P-glycoprotein; THR, total hip replacement; TKR, total knee replacement.

Dabigatran etexilate was evaluated in four phase III studies. Dabigatran etexilate ( $150 \mathrm{mg}$ or $220 \mathrm{mg}$ od) failed to show non-inferiority versus an enoxaparin regimen of $30 \mathrm{mg}$ bid in terms of efficacy (composite of any DVT, symptomatic PE, and all-cause mortality) in the RE-MOBILIZE study in TKR with a treatment duration of 12-15 days (39). However, non-inferiority was demonstrated versus an enoxaparin regimen of $40 \mathrm{mg}$ od in REMODEL (TKR; 6-10 days), RE-NOVATE, and RE-NOVATE II (THR; 28-35 days), and there were no significant differences in the rates of major bleeding (36-38). A meta-analysis of RE-MODEL, RE-NOVATE and RE-MOBILIZE was performed by Wolowacz et al., and the results of this were consistent with those of the individual studies.(47)

There was considerable variation in efficacy and safety outcomes for rivaroxaban, apixaban, dabigatran etexilate and enoxaparin across the studies described, reflecting differences in patient populations, treatment regimens, and safety outcome definitions ( Table 2). Definitions of efficacy endpoints were similar for all studies, and incidences of VTE were generally higher for patients undergoing TKR rather than THR surgery ( Table 2). Studies of dabigatran etexilate generally showed higher incidences of VTE than studies of rivaroxaban or apixaban for comparable indications.

Definitions of major bleeding varied across studies of rivaroxaban, apixaban, and dabigatran etexilate, confounding a direct comparison of major bleeding rates between the three agents. Nonetheless, incidences of major bleeding were generally low across all studies, with no clear separation between studies in patients undergoing THR or TKR surgery ( Table 2).

\section{VTE prevention in hospitalised acutely ill medical patients}

Evidence suggests that VTE prophylaxis in hospitalised acutely ill medical patients is under-used or used inappropriately (48-50). The ENDORSE study found that only 6,119 (39.5\%) of 15,487 enrolled acutely ill medical patients considered to be at risk of VTE received appropriate thromboprophylaxis (51). In the IMPROVE registry, approximately $60 \%$ of 15,156 patients classified as likely to benefit from pharmacological prophylaxis received appropriate prophylaxis (52). Other studies support these findings: the DVT FREE study found that only $42 \%$ of the 2,726 hospitalised acutely ill medical patients received thromboprophylaxis within the 30 days before DVT diagnosis (53); and in the CURVE study, although $90 \%$ of the 1,702 hospitalised medically ill medical patients had indications for thromboprophylaxis, only $16 \%$ received appropriate medication (54).

The lack of consensus on the most appropriate duration of thromboprophylaxis in acutely ill medical patients poses a challenge to clinicians. Several studies have assessed the benefits of 6-14 days (considered as the standard duration) of thromboprophylaxis in acutely ill medical patients $(6-8,55,56)$. MEDENOX (prophylaxis in medical patients with enoxaparin) was a doubleblind, randomised, placebo-controlled study with 1,102 hospitalised patients who were $>40$ years of age and received enoxaparin or placebo subcutaneously od for 6-14 days (7). ARTEMIS (fondaparinux for the prevention of VTE in older acutely ill medical patients) was a double-blind, randomised, placebo-controlled trial that included 849 hospitalised medical patients aged $\geq 60$ years who were expected to remain in bed for at least four days and received $2.5 \mathrm{mg}$ fondaparinux or placebo subcutaneously od for 6-14 days 
Table 2: Comparison of phase III studies of apixaban, rivaroxaban, and dabigatran etexilate for VTE prevention after total hip or knee replacement surgery.

\begin{tabular}{|c|c|c|c|}
\hline Study & Comparison & Primary efficacy outcome & Main safety outcome \\
\hline \multicolumn{4}{|l|}{ Rivaroxaban } \\
\hline RECORD1 & $\begin{array}{l}\text { Rivaroxaban } 10 \mathrm{mg} \text { od vs. enoxaparin } 40 \mathrm{mg} \\
\text { od (THR) }\end{array}$ & $\begin{array}{l}1.1 \% \text { vs. } 3.7 \% \text {, } \\
\text { respectively; } p<0.001 \text { for superiority }\end{array}$ & $\begin{array}{l}0.3 \% \text { vs. } 0.1 \%, \\
\text { respectively; } p=0.18\end{array}$ \\
\hline RECORD2 & $\begin{array}{l}\text { Rivaroxaban } 10 \mathrm{mg} \text { od vs. enoxaparin } 40 \mathrm{mg} \\
\text { od (THR) }\end{array}$ & $\begin{array}{l}2.0 \% \text { vs. } 9.3 \% \text {, respectively; } p<0.0001 \text { for } \\
\text { superiority }\end{array}$ & $<0.1 \%$ vs. $<0.1 \%$, respectively \\
\hline RECORD3 & $\begin{array}{l}\text { Rivaroxaban } 10 \mathrm{mg} \text { od vs. enoxaparin } 40 \mathrm{mg} \\
\text { od (TKR) }\end{array}$ & $\begin{array}{l}9.6 \% \text { vs. } 18.9 \% \text {, respectively; } p<0.001 \text { for } \\
\text { superiority }\end{array}$ & $\begin{array}{l}0.6 \% \text { vs. } 0.5 \% \\
\text { respectively; } p=0.77\end{array}$ \\
\hline RECORD4 & $\begin{array}{l}\text { Rivaroxaban } 10 \mathrm{mg} \text { od vs. enoxaparin } 30 \mathrm{mg} \\
\text { bid (TKR) }\end{array}$ & $\begin{array}{l}6.9 \% \text { vs. } 10.1 \% \text {, respectively; } p=0.0118 \text { for } \\
\text { superiority }\end{array}$ & $\begin{array}{l}0.7 \% \text { vs. } 0.3 \% \\
\text { respectively; } p=0.11^{*}\end{array}$ \\
\hline RECORD1-4 pooled ${ }^{\dagger}$ & $\begin{array}{l}\text { Rivaroxaban regimens vs. enoxaparin } \\
\text { regimens (THR and TKR) }\end{array}$ & $\begin{array}{l}\text { Day } 12 \pm 2 \text { active treatment period: } 0.5 \% \\
\text { vs. } 1.0 \% \text {, respectively; } p=0.001 \\
\text { Total treatment period: }{ }^{\ddagger} 0.6 \% \text { vs. } 1.3 \% \text {, re- } \\
\text { spectively }\end{array}$ & $\begin{array}{l}\text { Day } 12 \pm 2 \text { active treatment period: } 0.3 \% \\
\text { vs. } 0.2 \% \text {, respectively; } p=0.23 \\
\text { Total treatment period: }{ }^{\ddagger} 0.4 \% \text { vs. } 0.2 \% \text {, re- } \\
\text { spectively }\end{array}$ \\
\hline \multicolumn{4}{|l|}{ Apixaban } \\
\hline ADVANCE-1 & $\begin{array}{l}\text { Apixaban } 2.5 \mathrm{mg} \text { bid vs. enoxaparin } 30 \mathrm{mg} \\
\text { bid (TKR) }\end{array}$ & $\begin{array}{l}\text { Apixaban failed non-inferiority to enoxapa- } \\
\text { rin: } 9.0 \% \text { vs. } 8.8 \% \text {, respectively; } p=0.06 \text { for } \\
\text { non-inferiority }\end{array}$ & $\begin{array}{l}0.7 \% \text { vs. } 1.4 \% \\
\text { respectively; } p=0.05\end{array}$ \\
\hline ADVANCE-2 & $\begin{array}{l}\text { Apixaban } 2.5 \mathrm{mg} \text { bid vs. enoxaparin } 40 \mathrm{mg} \\
\text { od (TKR) }\end{array}$ & $\begin{array}{l}15.1 \% \text { vs. } 24.4 \% \text {, respectively; } p<0.0001 \\
\text { for non-inferiority and superiority }\end{array}$ & $\begin{array}{l}0.6 \% \text { vs. } 0.9 \% \\
\text { respectively; } p=0.30^{*}\end{array}$ \\
\hline ADVANCE-3 & $\begin{array}{l}\text { Apixaban } 2.5 \mathrm{mg} \text { bid vs. enoxaparin } 40 \mathrm{mg} \\
\text { od (THR) }\end{array}$ & $\begin{array}{l}1.4 \% \text { vs. } 3.9 \% \text {, respectively; } p<0.001 \text { for } \\
\text { non-inferiority and superiority }\end{array}$ & $\begin{array}{l}0.8 \% \text { vs. } 0.7 \% \\
\text { respectively; } p=0.54\end{array}$ \\
\hline $\begin{array}{l}\text { ADVANCE-1, AD- } \\
\text { VANCE-2, and phase II } \\
\text { study pooled }\end{array}$ & $\begin{array}{l}\text { Apixaban regimens vs. enoxaparin regimens } \\
\text { (TKR) }\end{array}$ & $\begin{array}{l}\text { Proximal DVT: } 0.6 \% \text { vs. } 1.2 \% \text {, respectively; } \\
p=0.007 \\
\text { PE: } 0.6 \% \text { vs. } 0.3 \% ; p=0.055\end{array}$ & $\begin{array}{l}0.6 \% \text { vs. } 1.2 \% \\
\text { respectively; } p=0.034\end{array}$ \\
\hline \multicolumn{4}{|l|}{ Dabigatran etexilate } \\
\hline RE-MODEL & $\begin{array}{l}\text { Dabigatran etexilate } 150 \mathrm{mg} \text { od or } 220 \mathrm{mg} \\
\text { od vs. enoxaparin } 40 \mathrm{mg} \text { od (TKR) }\end{array}$ & $\begin{array}{l}\text { Both doses non-inferior to enoxaparin: } \\
40.5 \%(150 \mathrm{mg}) \text { and } 36.4 \%(220 \mathrm{mg}) \text { vs. } \\
37.7 \% \text {, respectively; } \mathrm{p}=0.82(150 \mathrm{mg}) \text {, } \\
\mathrm{p}=0.38(220 \mathrm{mg})\end{array}$ & $\begin{array}{l}1.3 \%(150 \mathrm{mg}) \text { and } 1.5 \%(220 \mathrm{mg}) \text { vs. } \\
1.3 \% \text {, respectively; } p=1.0(150 \mathrm{mg}), p=0.82 \\
(220 \mathrm{mg})\end{array}$ \\
\hline RE-NOVATE & $\begin{array}{l}\text { Dabigatran etexilate } 150 \mathrm{mg} \text { od or } 220 \mathrm{mg} \\
\text { od vs. enoxaparin } 40 \mathrm{mg} \text { od (THR) }\end{array}$ & $\begin{array}{l}\text { Both doses non-inferior to enoxaparin: } 8.6 \% \\
(150 \mathrm{mg}) \text { and } 6.0 \% \text { ( } 220 \mathrm{mg}) \text { vs. } 6.7 \% \text {, re- } \\
\text { spectively; } p<0.0001 \text { (150 mg), } p<0.0001 \\
\text { ( } 220 \mathrm{mg} \text { ) (both for non-inferiority) }\end{array}$ & $\begin{array}{l}1.3 \%(150 \mathrm{mg}) \text { and } 2.0 \%(220 \mathrm{mg}) \mathrm{vs} . \\
1.6 \% \text {, respectively; } p=0.60(150 \mathrm{mg}) \\
\mathrm{p}=0.44(220 \mathrm{mg})\end{array}$ \\
\hline RE-NOVATE II & $\begin{array}{l}\text { Dabigatran etexilate } 220 \mathrm{mg} \text { od vs. enoxapa- } \\
\text { rin } 40 \mathrm{mg} \text { od (THR) }\end{array}$ & $\begin{array}{l}\text { Dabigatran non-inferior to enoxaparin: } 7.7 \% \\
\text { vs. } 8.8 \% \text {, respectively; } p<0.0001 \text { for non-in- } \\
\text { feriority }\end{array}$ & $1.4 \%$ vs. $0.9 \%$, respectively; $p=0.40$ \\
\hline RE-MOBILIZE & $\begin{array}{l}\text { Dabigatran etexilate } 150 \mathrm{mg} \text { od or } 220 \mathrm{mg} \\
\text { od vs. enoxaparin } 30 \mathrm{mg} \text { bid (TKR) }\end{array}$ & $\begin{array}{l}\text { Both doses failed non-inferiority to enoxapa- } \\
\text { rin: } 33.7 \% \text { ( } 150 \mathrm{mg}) \text { and } 31.1 \%(220 \mathrm{mg}) \\
\text { vs. } 25.3 \% \text {, respectively; } p=0.0009(150 \mathrm{mg}) \text {, } \\
p=0.0234(220 \mathrm{mg})\end{array}$ & $\begin{array}{l}0.6 \%(150 \mathrm{mg}) \text { and } 0.6 \%(220 \mathrm{mg}) \text { vs. } \\
1.4 \% \text {, respectively }\end{array}$ \\
\hline Dabigatran pooled $^{\dagger}$ & $\begin{array}{l}\text { Dabigatran etexilate regimens vs. enoxaparin } \\
\text { (THR and TKR) }\end{array}$ & $\begin{array}{l}3.8 \%(150 \mathrm{mg}) \text { and } 3.0 \%(220 \mathrm{mg}) \text { vs. } \\
3.3 \% \text {, respectively; } p=0.91(150 \mathrm{mg}) \text {, } \\
\mathrm{p}=0.20(220 \mathrm{mg})\end{array}$ & $\begin{array}{l}1.1 \%(150 \mathrm{mg}) \text { and } 1.4 \%(220 \mathrm{mg}) \text { vs. } \\
1.4 \% \text {, respectively; } p=0.54(150 \mathrm{mg}) \\
p=0.19(220 \mathrm{mg})\end{array}$ \\
\hline
\end{tabular}

${ }^{*} \mathrm{p}$-value rounded up to two decimal points. ${ }^{\dagger}$ Both primary outcomes excluded asymptomatic events. ${ }^{\ddagger}$ Planned treatment period for double-blind study medication for each RECORD study, including the placebo phase in RECORD2. bid, twice daily; DVT, deep-vein thrombosis; THR, total hip replacement; TKR, total knee replacement; od, once daily; PE, pulmonary embolism.

(6). PREVENT (prospective evaluation of dalteparin efficacy for prevention of VTE in immobilised patients) was an international, multicentre, randomised, double-blind, placebo-controlled trial that included 3,706 patients receiving subcutaneous dalteparin
5,000 IU daily or placebo for 14 days (8). These studies showed significant reductions in VTE without a significant increase in the risk of bleeding. However, this duration of thromboprophylaxis may not provide adequate protection against VTE after hospital dis- 
charge in at-risk acutely ill medical patients (20). In one study, $36.8 \%$ of patients developed VTE in the outpatient setting within three months of hospitalisation (57). A recent study in 3,039 patients admitted to post-acute care facilities after medical disease or surgery showed that $2.4 \%$ developed VTE within a median of 13 days, although $75.1 \%$ received thromboprophylaxis. Multivariate Cox regression analysis identified previous VTE (hazard ratio [HR] 5.67, 95\% confidence interval [CI] 3.30-9.77; $<<0.001)$ and cancer (HR 2.26, 95\% CI 1.36-3.75; $\mathrm{p}<0.01$ ) as conditions that were significantly associated with the occurrence of VTE (58).

The EXCLAIM study (extended prophylaxis for VTE in acutely ill medical patients with prolonged immobilisation) aimed to determine whether there was a benefit for extended-duration ( $28 \pm 4$ days) compared with standard-duration (10 \pm 4 days) thromboprophylaxis with enoxaparin $40 \mathrm{mg}$ od. In this study, all patients had previously received open-label enoxaparin for two weeks. After randomisation to placebo for standard-duration therapy or enoxaparin for extended-duration therapy, events were analysed between day 10 and day 38 . The inclusion criteria were hospitalisation for a medical illness, age $\geq 40$ years, life expectancy of at least six months, and reduced mobility level 1 (defined as total bed rest or sedentary) or level 2 (defined as level 1 with bathroom privileges; after interim analyses of efficacy and safety outcomes, the definition of level 2 immobility was revised to include $\geq 1$ risk factor for VTE, including age $>75$ years, previous VTE, and active or previous cancer) (9). Analysis of the total patient population found that extended-duration enoxaparin reduced the risk of VTE when compared with placebo ( $2.5 \%$ vs. $4.0 \%$, respectively; absolute risk difference $-1.53 \%$ [95\% CI -2.54 to -0.52$]$ ). However, the rate of major bleeding events was significantly higher in the extended-duration enoxaparin group versus the placebo group ( $0.8 \%$ vs. $0.3 \%$, respectively; absolute risk difference $0.51 \%$ [ $95 \%$ CI 0.12-0.89]). Subgroup analyses found that the benefit of extended-duration enoxaparin was restricted to women, patients $>75$ years of age, and those with mobility level 1 .

Rivaroxaban has been evaluated in the MAGELLAN study: a multicentre, randomised, parallel-group efficacy and safety study for the prevention of VTE in hospitalised acutely ill medical patients that compared rivaroxaban with enoxaparin $(10,42)$. A total of 8,101 patients were randomised to receive either subcutaneous enoxaparin $40 \mathrm{mg}$ od for $10 \pm 4$ days followed by placebo, or oral rivaroxaban $10 \mathrm{mg}$ od for $35 \pm 4$ days. Patients were eligible if they were hospitalised for an acute medical illness, aged $\geq 40$ years, at risk of VTE, and had a life expectancy of at least six months. Those with acute infectious, inflammatory, or rheumatic diseases and those with acute respiratory insufficiency were required to have at least one additional risk factor for VTE (e.g. history of VTE or cancer). The primary efficacy outcomes of this study were the composite of asymptomatic proximal DVT, symptomatic DVT (proximal or distal), symptomatic non-fatal PE, and VTE-related death at day $10+5$ (test for non-inferiority) or at day $35+6$ (test for superiority). Rivaroxaban was non-inferior in reducing risk of VTE when compared with enoxaparin at day 10 (2.7\% vs. $2.7 \%$, $\mathrm{p}=0.0025)$, but was superior at day 35 when compared with enoxaparin followed by placebo $(4.4 \%$ and $5.7 \%$ respectively; $\mathrm{p}=0.0211$ ). Clinically relevant bleeding, the composite of major bleeding and non-major clinically relevant bleeding, was assessed as the principal safety outcome. Overall rates of clinically relevant bleeding were low, but were significantly higher in patients receiving rivaroxaban than in patients receiving enoxaparin $(4.1 \%$ vs. $1.7 \%$ respectively, $\mathrm{p}<0.0001$ for events between day 1 and day 35 ). There were no significant differences in rates of other adverse events including liver and cardiovascular events, and all-cause mortality (10).

The double-blind, multicentre ADOPT study compared extended-duration ( 30 days) apixaban $2.5 \mathrm{mg}$ bid with standard-duration (6-14 days) enoxaparin $40 \mathrm{mg}$ od (43). Patients were eligible if they were $\geq 40$ years of age and were hospitalised (expected stay of at least three days) with congestive heart failure, respiratory failure, or other medical disorders, and had at least one additional risk factor for VTE. A total of 6,528 patients were randomised, 4,495 of whom were evaluated for the primary efficacy outcome, defined as the 30-day composite of VTE-related death, PE, symptomatic DVT (proximal or distal), or asymptomatic proximal-leg DVT as detected by systematic bilateral compression ultrasonography. The primary efficacy outcome occurred in 60 of 2,211 patients (2.71\%) of patients in the apixaban group and in 70 of 2,284 patients $(3.06 \%)$ in the enoxaparin group (relative risk $[R R]$ with apixaban $0.87 ; 95 \% \mathrm{CI} 0.62-1.23 ; \mathrm{p}=0.44$ ). The primary safety outcome was major bleeding; during the 30 -day treatment period, this outcome occurred in $0.47 \%$ of patients receiving apixaban and in $0.19 \%$ of patients receiving enoxaparin (RR 2.58; 95\% CI 1.02-7.24; $\mathrm{p}=0.04$ ). Major plus non-major clinically relevant bleeding occurred in $2.67 \%$ versus $2.08 \%$ of patients, respectively (RR 1.28 ; 95\% CI 0.93-1.76).

The study designs of MAGELLAN and ADOPT were broadly similar $(10,42,43)$. The two studies both enrolled acutely ill medical patients at risk of VTE, had a comparator arm in common - enoxaparin $40 \mathrm{mg}$ od for $10 \pm 4$ days (MAGELLAN) or 6-14 days (ADOPT) - and evaluated extended-duration thromboprophylaxis. The primary efficacy outcome was also similarly defined for the two studies. However, the outcomes of the studies differed; in the MAGELLAN study, extended-duration rivaroxaban was shown to be significantly more effective than standard-duration enoxaparin for VTE prevention (10), whereas in ADOPT, extended-duration apixaban was shown to be not superior to enoxaparin (43). In both studies the risk of bleeding was increased with extended-duration regimens.

Most evidence for VTE prophylaxis in patients with cancer comes from subgroup analyses of general surgery studies. There is a need for studies of VTE prophylaxis in patients with cancer alone that will differentiate between ambulatory and hospitalised cancer patients. In one of the few investigations of ambulatory patients with advanced cancer, the PROTECHT (PRophylaxis of ThromboEmbolism during CHemoTherapy) study showed that the LMWH nadroparin given for the duration of chemotherapy up to four months significantly reduced the incidence of thromboembolic events compared with placebo ( $2.0 \%$ vs. $3.9 \%$, respectively; $\mathrm{p}=0.02$ ), with no significant difference in the rates of major bleeding events (59). Trials of the newer oral anticoagulants rivaroxaban 
(MAGELLAN study) and apixaban (ADOPT study) include patients with cancer, and subgroup analyses of these data will help to increase our understanding of the potential role of new oral anticoagulants in VTE prevention in patients with cancer.

\section{Discussion}

The benefits of both short (after TKR) and extended (after THR and HFS) pharmacological thromboprophylaxis after major orthopaedic surgery are well established and this is reflected in VTE prevention guidelines (3). In hospitalised acutely ill medical patients at risk of VTE, clinical trials have shown that short-term (6-14 days) thromboprophylaxis reduces the risk of VTE, although the optimal duration of thromboprophylaxis in these patients is not known.

The average length of hospital stay for critical care, medical, and surgical patients at risk of VTE is only 5.3 days (60), meaning that patients who discontinue thromboprophylaxis when discharged from hospital are at continued risk of VTE. Therefore, there is a clinical need for anticoagulants that are effective and convenient to use, particularly in the outpatient setting. In addition, from an economic perspective, a reduction in VTE rates that is achieved by using extended-duration prophylaxis compared with standardduration therapy in at-risk medical and surgical patients could be more cost-effective $(20,61)$.

Despite the availability of effective anticoagulant therapies and guideline recommendations, many patients (both surgical and non-surgical) do not receive appropriate VTE prophylaxis in both the inpatient and post-discharge settings $(3,60,62,63)$. One study found that an estimated $36.8 \%$ of all at-risk patients did not receive any thromboprophylaxis in hospital (60). Another study indicated that $24.9 \%$ of patients after medical disease or surgery who were at risk of VTE did not receive thromboprophylaxis in post-acute care facilities, and in an additional study only $54.4 \%$ of orthopaedic surgery patients had filled a prescription for thromboprophylaxis 30 days after discharge $(58,64)$. A reason for suboptimal thromboprophylaxis in these patient groups may be the limitations of traditional anticoagulants, such as the need for daily subcutaneous injections of UFH, LMWH, or fondaparinux - posing a particular problem with compliance in the outpatient setting - or the requirement for routine coagulation monitoring, or the presence of food and drug interactions (65).

The newer oral anticoagulants - rivaroxaban, apixaban, and dabigatran etexilate - may have an advantage over parenteral agents, particularly for patients who require prolonged thromboprophylaxis, because they can be administered orally as a fixed dose without routine coagulation monitoring. These agents have demonstrated superior efficacy for VTE prevention after THR or TKR surgery without increasing the risk of bleeding $(28-31,34-37,39)$. In addition, both extended-duration rivaroxaban and apixaban have been evaluated compared with standard-duration enoxaparin for VTE prevention in hospitalised acutely ill medical patients; rivaroxaban showed superior efficacy and apixaban showed simi- lar efficacy to enoxaparin $(10,42,43)$. Rivaroxaban, but not apixaban, recorded a significant increase in the risk of clinically relevant bleeding, compared with enoxaparin.

Most clinical data for the newer oral anticoagulants have demonstrated equal or superior efficacy compared with LMWHs (66). However, the risk of bleeding complications persists, reinforcing the importance of evaluating the full benefit-risk profile of an antithrombotic agent when considering its role in real-life clinical practice (66).

The increased risk of bleeding observed in acutely ill medical patients receiving extended thromboprophylaxis compared with major orthopaedic surgery patients is likely a result of the differing patient populations. Data from the IMPROVE registry identified factors associated with increased bleeding risk in acutely ill patients; these factors include active gastroduodenal ulcer, prior bleeding, and low platelet count. Risk factors for bleeding also included increased age, hepatic or renal failure, intensive care unit stay, central venous catheter, rheumatic disease, cancer, and male gender (67). In comparison with hospitalised acutely ill medical patients, patients undergoing elective major orthopaedic surgery procedures are likely to be younger and fitter and therefore at reduced risk of bleeding events.

The characteristics of the newer oral anticoagulants may increase adherence to thromboprophylaxis guidelines, thereby reducing rates of VTE and consequently morbidity and mortality (3). The evidence provided by the large randomised trials of these newer oral anticoagulants is likely to contribute to updated guidelines and recommendations for VTE prevention in the future. However, further research is still necessary in acutely ill medical patients to determine if there are patient subgroups that might benefit from extended thromboprophylaxis.

\section{Acknowledgements}

The authors would like to acknowledge Claudia Wiedemann, who provided editorial support with funding from Bayer HealthCare Pharmaceuticals and Janssen Research \& Development, L.L.C. (formerly Johnson \& Johnson Pharmaceutical Research \& Development, L.L.C.).

\section{Conflicts of interest}

Dr Ageno has received honoraria from Bayer HealthCare, Bristol-Myers Squibb, Pfizer, Boehringer Ingelheim, and sanofi-aventis. Dr Spyropoulos has received honoraria as a consultant for Bayer HealthCare, Eisai, Boehringer Ingelheim, Bristol-Myers Squibb, Pfizer, and sanofi-aventis. Dr Spyropoulos is also on the Drug Safety Monitoring Board for Astellas and on the Steering Committee for Bayer HealthCare. Dr Turpie has been a consultant to Bayer HealthCare, Johnson \& Johnson, Astellas, Portola, and Takeda.

\section{References}

1. Spyropoulos AC, Mahan C. Venous thromboembolism prophylaxis in the medical patient: controversies and perspectives. Am J Med 2009; 122: 1077-1084.

2. Dobesh PP. Economic burden of venous thromboembolism in hospitalized patients. Pharmacotherapy 2009; 29: 943-953. 
3. Geerts WH, Bergqvist D, Pineo GF, et al. Prevention of venous thromboembolism: American College of Chest Physicians evidence-based clinical practice guidelines (8th Edition). Chest 2008; 133: 381S-453S.

4. Heit JA, Silverstein MD, Mohr DN, et al. Risk factors for deep vein thrombosis and pulmonary embolism: a population-based case-control study. Arch Intern Med 2000; 160: 809-815.

5. Khorana AA. Cancer and thrombosis: implications of published guidelines for clinical practice. Ann Oncol 2009; 20: 1619-1630.

6. Cohen AT, Davidson BL, Gallus AS, et al. Efficacy and safety of fondaparinux for the prevention of venous thromboembolism in older acute medical patients: randomised placebo controlled trial. Br Med J 2006; 332: 325-329.

7. Samama MM, Cohen AT, Darmon JY, et al. A comparison of enoxaparin with placebo for the prevention of venous thromboembolism in acutely ill medical patients. Prophylaxis in Medical Patients with Enoxaparin Study Group. N Engl J Med 1999; 341: 793-800.

8. Leizorovicz A, Cohen AT, Turpie AGG, et al. Randomized, placebo-controlled trial of dalteparin for the prevention of venous thromboembolism in acutely ill medical patients. Circulation 2004; 110: 874-879.

9. Hull RD, Schellong SM, Tapson VF, et al. Extended-duration venous thromboembolism prophylaxis in acutely ill medical patients with recently reduced mobility: a randomized trial. Ann Intern Med 2010; 153: 8-18.

10. Cohen AT, Spiro TE, Büller HR, et al. Rivaroxaban compared with enoxaparin for the prevention of venous thromboembolism in acutely ill medical patients. American College of Cardiology Congress 60th Annual Scientific Session. New Orleans, USA, 2-5 April 2011; Oral presentation.

11. Becattini C, Lignani A, Agnelli G. New anticoagulants for the prevention of venous thromboembolism. Drug Des Devel Ther 2010; 4: 49-60.

12. Prandoni P, Samama MM. Risk stratification and venous thromboprophylaxis in hospitalized medical and cancer patients. Br J Haematol 2008; 141: 587-597.

13. Turpie AGG, Leizorovicz A. Prevention of venous thromboembolism in medically ill patients: a clinical update. Postgrad Med J 2006; 82: 806-809.

14. Anderson FA, Jr., Spencer FA. Risk factors for venous thromboembolism. Circulation 2003; 107: I9-I16.

15. Anderson FA, Jr., Wheeler HB, Goldberg RJ, et al. A population-based perspective of the hospital incidence and case-fatality rates of deep vein thrombosis and pulmonary embolism. The Worcester DVT Study. Arch Intern Med 1991; 151: 933-938.

16. Barbar S, Noventa F, Rossetto V, et al. A risk assessment model for the identification of hospitalized medical patients at risk for venous thromboembolism: The Padua Prediction Score. J Thromb Haemost 2010; 8: 2450-2457.

17. Spyropoulos AC. Risk assessment of venous thromboembolism in hospitalized medical patients. Curr Opin Pulm Med 2010; 16: 419-425.

18. Connolly GC, Khorana AA. Emerging risk stratification approaches to cancer-associated thrombosis: risk factors, biomarkers and a risk score. Thromb Res 2010; 125 (Suppl 2): S1-S7.

19. American Academy of Orthopaedic Surgeons. Preventing venous thromboembolic disease in patients undergoing elective hip and knee arthroplasty: evidencebased guideline and evidence report. Available at: http://www.aaos.org/Research/ guidelines/VTE/VTE_full_guideline.pdf. Accessed December 21, 2011.

20. Huo MH, Muntz J. Extended thromboprophylaxis with low-molecular-weight heparins after hospital discharge in high-risk surgical and medical patients: a review. Clin Ther 2009; 31: 1129-1141.

21. Nicolaides AN, Fareed J, Kakkar AK, et al. Prevention and treatment of venous thromboembolism. International Consensus Statement (guidelines according to scientific evidence). Int Angiol 2006; 25: 101-161.

22. Lyman GH, Khorana AA, Falanga A, et al. American Society of Clinical Oncology guideline: recommendations for venous thromboembolism prophylaxis and treatment in patients with cancer. J Clin Oncol 2007; 25: 5490-5505.

23. Spyropoulos AC. Outpatient-based primary and secondary thromboprophylaxis with low-molecular-weight heparin. Clin Appl Thromb Hemost 2008; 14: 63-74.

24. Ufer M. Comparative efficacy and safety of the novel oral anticoagulants dabigatran, rivaroxaban and apixaban in preclinical and clinical development. Thromb Haemost 2010; 103: 572-585.

25. Bayer Pharma AG. Xarelto (rivaroxaban) Summary of Product Characteristics. 2011. Available at: http://www.medicines.org.uk/EMC/medicine/21265/. Accessed January 4, 2012.

26. Bristol-Myers Squibb, Pfizer EEIG. Eliquis (apixaban) Summary of Product Characteristics. 2011. Available at: http://www.medicines.org.uk/EMC/medi cine/24988/. Accessed January 4, 2012.
27. Boehringer Ingelheim International GmbH. Pradaxa (dabigatran etexilate) Summary of Product Characteristics. 2011. Available at: http://www.medicines.org uk/emc/medicine/20760. Accessed January 4, 2012.

28. Eriksson BI, Borris LC, Friedman RJ, et al. Rivaroxaban versus enoxaparin for thromboprophylaxis after hip arthroplasty. N Engl J Med 2008; 358: 2765-2775.

29. Kakkar AK, Brenner B, Dahl OE, et al. Extended duration rivaroxaban versus short-term enoxaparin for the prevention of venous thromboembolism after total hip arthroplasty: a double-blind, randomised controlled trial. Lancet 2008; 372: 31-39.

30. Lassen MR, Ageno W, Borris LC, et al. Rivaroxaban versus enoxaparin for thromboprophylaxis after total knee arthroplasty. N Engl J Med 2008; 358:2776-2786.

31. Turpie AGG, Lassen MR, Davidson BL, et al. Rivaroxaban versus enoxaparin for thromboprophylaxis after total knee arthroplasty (RECORD4): a randomised trial. Lancet 2009; 373: 1673-1680.

32. Turpie AGG, Lassen MR, Eriksson BI, et al. Rivaroxaban for the prevention of venous thromboembolism after hip or knee arthroplasty. Pooled analysis of four studies. Thromb Haemost 2011; 105: 444-453.

33. Lassen MR, Raskob GE, Gallus A, et al. Apixaban or enoxaparin for thromboprophylaxis after knee replacement. N Engl J Med 2009; 361: 594-604.

34. Lassen MR, Raskob GE, Gallus A, et al. Apixaban versus enoxaparin for thromboprophylaxis after knee replacement (ADVANCE-2): a randomised double-blind trial. Lancet 2010; 375: 807-815.

35. Lassen MR, Gallus A, Raskob GE, et al. Apixaban versus enoxaparin for thromboprophylaxis after hip replacement. N Engl J Med 2010; 363: 2487-2498.

36. Eriksson BI, Dahl OE, Rosencher N, et al. Oral dabigatran etexilate vs. subcutaneous enoxaparin for the prevention of venous thromboembolism after total knee replacement: the RE-MODEL randomized trial. J Thromb Haemost 2007; 5: 2178-2185.

37. Eriksson BI, Dahl OE, Rosencher N, et al. Dabigatran etexilate versus enoxaparin for prevention of yenous thromboembolism after total hip replacement: a randomised, double-blind, non-inferiority trial. Lancet 2007; 370: 949-956.

38. Eriksson BI, Dahl OE, Huo MH, et al. Oral dabigatran versus enoxaparin for thromboprophylaxis after primary total hip arthroplasty (RE-NOVATE II). A randomised, double-blind, non-inferiority trial. Thromb Haemost 2011; 105: 721-729.

39. The RE-MOBILIZE Writing Committee. Oral thrombin inhibitor dabigatran etexilate vs North American enoxaparin regimen for prevention of venous thromboembolism after knee arthroplasty surgery. J Arthroplasty 2009; 24: 1-9.

40. Friedman RJ, Dahl OE, Rosencher N, et al. Dabigatran versus enoxaparin for prevention of venous thromboembolism after hip or knee arthroplasty: A pooled analysis of three trials. Thromb Res 2010; 126: 175-182.

41. Mavrakanas T, Bounameaux H. The potential role of new oral anticoagulants in the prevention and treatment of thromboembolism. Pharmacol Ther 2011; 130: $46-58$.

42. Cohen AT, Spiro TE, Büller HR, et al. Extended-duration rivaroxaban thromboprophylaxis in acutely ill medical patients: MAGELLAN study protocol. J Thromb Thrombolysis 2011; 31: 407-416.

43. Goldhaber SZ, Leizorovicz A, Kakkar AK, et al. Apixaban versus enoxaparin for thromboprophylaxis in medically ill patients. N Engl J Med 2011;365:2167-2177.

44. Ginzburg E, Dujardin F. Physicians' perceptions of the definition of major bleeding in major orthopedic surgery: results of an international survey. J Thromb Thrombolysis 2011; 31: 188-195.

45. Friedman RJ, Gallus AS, Cushner FD, et al. Physician compliance with guidelines for deep-vein thrombosis prevention in total hip and knee arthroplasty. Curr Med Res Opin 2008; 24: 87-97.

46. Huang J, Cao Y, Liao C, et al. Apixaban versus enoxaparin in patients with total knee arthroplasty. A meta-analysis of randomised trials. Thromb Haemost 2011; 105: 245-253.

47. Wolowacz SE, Roskell NS, Plumb JM, et al. Efficacy and safety of dabigatran etexilate for the prevention of venous thromboembolism following total hip or knee arthroplasty. A meta-analysis. Thromb Haemost 2009; 101: 77-85.

48. Abdel-Razeq H. Venous thromboembolism prophylaxis for hospitalized medical patients, current status and strategies to improve. Ann Thorac Med 2010; 5: 195-200.

49. Jaffer AK, Amin AN, Brotman DJ, et al. Prevention of venous thromboembolism in the hospitalized medical patient. Cleve Clin J Med 2008; 75 (Suppl 3):S7-S16.

50. Goldhaber SZ. Eradication of hospital-acquired venous thromboembolism. Thromb Haemost 2010; 104: 1089-1092.

51. Cohen AT, Tapson VF, Bergmann JF, et al. Venous thromboembolism risk and pro- 
phylaxis in the acute hospital care setting (ENDORSE study): a multinational cross-sectional study. Lancet 2008; 371: 387-394.

52. Tapson VF, Decousus H, Pini M, et al. Venous thromboembolism prophylaxis in acutely ill hospitalized medical patients: Findings from the International Medical Prevention Registry on Venous Thromboembolism. Chest 2007; 132: 936-945.

53. Goldhaber SZ, Tapson VF. A prospective registry of 5,451 patients with ultrasound-confirmed deep vein thrombosis. Am J Cardiol 2004; 93: 259-262.

54. Kahn SR, Panju A, Geerts W, et al. Multicenter evaluation of the use of venous thromboembolism prophylaxis in acutely ill medical patients in Canada. Thromb Res 2007; 119: 145-155.

55. Kleber FX, Witt C, Vogel G, et al. Randomized comparison of enoxaparin with unfractionated heparin for the prevention of venous thromboembolism in medical patients with heart failure or severe respiratory disease. Am Heart J 2003; 145: 614-621.

56. Lechler E, Schramm W, Flosbach CW. The venous thrombotic risk in non-surgical patients: epidemiological data and efficacy/safety profile of a low-molecularweight heparin (enoxaparin). The Prime Study Group. Haemostasis 1996; 26 (Suppl 2): 49-56.

57. Spencer FA, Lessard D, Emery C, et al. Venous thromboembolism in the outpatient setting. Arch Intern Med 2007; 167: 1471-1475.

58. Scannapieco G, Ageno W, Airoldi A, et al. Incidence and predictors of venous thromboembolism in post-acute care patients. A prospective cohort study. Thromb Haemost 2010; 104: 734-740.

59. Agnelli G, Gussoni G, Bianchini C, et al. Nadroparin for the prevention of thromboembolic events in ambulatory patients with metastatic or locally advanced solid cancer receiving chemotherapy: a randomised, placebo-controlled, doubleblind study. Lancet Oncol 2009; 10: 943-949.

60. Amin A, Spyropoulos AC, Dobesh P, et al. Are hospitals delivering appropriate VTE prevention? The venous thromboembolism study to assess the rate of thromboprophylaxis (VTE start). J Thromb Thrombolysis 2010; 29: 326-339.

61. Sarasin FP, Bounameaux H. Out of hospital antithrombotic prophylaxis after total hip replacement: low-molecular-weight heparin, warfarin, aspirin or nothing? A cost-effectiveness analysis. Thromb Haemost 2002; 87: 586-592.

62. Warwick D, Friedman RJ, Agnelli G, et al. Insufficient duration of venous thromboembolism prophylaxis after total hip or knee replacement when compared with the time course of thromboembolic events: findings from the Global Orthopaedic Registry. J Bone Joint Surg Br 2007; 89: 799-807.

63. Caprini JA, Hyers TM. Compliance with antithrombotic guidelines: Current practice, barriers, and strategies for improvement. Manag Care 2006; 15: 49-66.

64. Amin AN, Lin J, Ryan A. Need to improve thromboprophylaxis across the continuum of care for surgical patients. Adv Ther 2010; 27: 81-93.

65. Spyropoulos AC. Brave new world: the current and future use of novel anticoagulants. Thromb Res 2008; 123 (Suppl 1): S29-S35.

66. Huo MH. New oral anticoagulants in venous thromboembolism prophylaxis in orthopaedic patients: are they really better? Thromb Haemost 2011; 106: 45-57.

67. Decousus H, Tapson VF, Bergmann JF, et al. Factors at admission associated with bleeding risk in medical patients: findings from the IMPROVE investigators. Chest 2011; 139: 69-79. 